Marquette University

e-Publications@Marquette

Psychology Faculty Research and Publications

Psychology, Department of

$11-1-2010$

\title{
Shyness and Online Social Networking Services
}

Levi Baker

Marquette University

Debra Oswald

Marquette University, debra.oswald@marquette.edu

Accepted version. Journal of Social and Personal Relationships, Volume 27, No. 7 (November 2010): 873-889, DOI. (C) 2010 SAGE Publications. Used with permission. 


\title{
Shyness and Online Social Networking Services
}

\author{
Levi R. Baker \\ Department of Psychology, University of Tennessee \\ Knoxville, $T N$ \\ Debra L. Oswald \\ Department of Psychology, Marquette University \\ Milwaukee, WI
}

\begin{abstract}
Online social networking services are Internet websites that allow individuals to learn about and communicate with others. This study investigated the association between use of these websites and friendship quality for individuals varying in shyness. Participants $(N=241)$ completed questionnaires assessing their use of Facebook, an online social networking service, shyness, perceived available social support, loneliness, and friendship quality. Results indicated an interaction between shyness and Facebook usage, such that individuals high in shyness (when compared to less shy individuals) reported stronger associations between Facebook use and friendship quality. Facebook use, however, was unrelated to loneliness among highly shy individuals. Therefore, online social networking services may provide a comfortable within which shy individuals can interact with others.

Shy individuals experience difficulties establishing close and satisfying relationships (Asendorpf, 2000) due to the social anxiety that they experience during social interaction (Cheek \& Busch, 1981). This anxiety causes them to inhibit social behavior or avoid social interaction altogether. In turn, shy individuals report receiving less
\end{abstract}


support from, and feeling less close to, their peers than do less shy individuals (Asendorpf, 2000; Jones \& Carpenter, 1986). Because shy individuals often report poor quality friendships, it is important to identify contexts that can facilitate high quality relationships for shy individuals.

The Internet may provide one context that facilitates better quality relationships for shy individuals because many of their social difficulties (e.g., avoidance, inhibition) are reduced online (Brunet \& Schmidt, 2007; McKenna, Green, \& Gleason, 2002; Roberts, Smith, \& Pollock, 2000). This has led some scholars (McKenna et al., 2002; Roberts et al., 2000) to suggest that the online environment may provide a comfortable environment for shy individuals to interact with others. Although shy individuals may behave more confidently online, we know little about the relationship between shy individuals' actual friendships and their online communication.

The present study's goal is to examine how online social networking services (i.e., websites that allow users to communicate and learn about others), are associated with the quality of college students' friendships across levels of shyness. Therefore, we describe how shy individuals behave in social situations, why their behavior differs from less shy individuals, and why online social networking sites may be attractive for shy individuals.

\section{Shy individuals' social difficulties}

Shy individuals' behaviors often hinder peer relationships. First, compared to the less shy, shy people often avoid social situations (Alden \& Phillips, 1990), such as dating (Arkowitz, Hinton, Perl, \& Himadi, 1978; Heimberg, Harrison, Montgomery, Madsen, \& Sherfey, 1980), sitting and living near others (McCroskey, 1976), and everyday interactions (Dodge, Heimberg, Nyman, \& O'Brian, 1987). Second, when shy people do interact with others, compared to the less shy, they rarely initiate conversations (Mandel \& Shrauger, 1980; Pilkonis, 1977), speak less (Cheek \& Buss, 1981; Leary \& Kowalski, 1995; Mandel \& Shrauger, 1980; Pilkonis, 1977), rarely disagree with others (Leary, Knight, \& Johnson, 1987), ask fewer questions (Hill, 1989), rarely self-disclose (Meleshko \& Alden, 1993), and avoid eye-contact (Cheek \& Buss, 1981; Garcia, Stinson, Ickes, Bissonnette, \& Briggs, 1991). 
Shy individuals also struggle to maintain intimacy in close relationships (for review, see Weaver, 1987) and have poor social networks (Nelson et al., 2008). Asendorpf (2000) found that shy individuals spent less time engaged in social interactions, felt less close with peers, and received less support from peers than did nonshy individuals. Similarly, Jones and Carpenter (1986) found that shy people received less advice and guidance, felt less close and connected, received fewer assurances of worth, less support, and felt less assurance that they could count on others.

\section{Theories of shyness}

Given their social avoidance and inhibition, one might assume that shy people desire less social contact than do less shy people. Shy people, however, vary in desired levels of social contact, and do not differ on average from the less shy in their desire for social contact. Shyness theories (e.g. Asendorpf, 1990; Buss, 1986; Schmidt \& Fox, 1999) propose that, although some individuals withdraw because they lack social approach motivation, others withdraw because they feel unable to enter social situations. Furthermore, Cheek and Buss (1981) demonstrated that shyness and sociability are orthogonal, suggesting that being shy does not necessarily equate to desiring less social contact. Finally, compared to the less shy, shy individuals report being Ionelier (Cheek \& Busch, 1981; Neto, 1992) and less socially satisfied (Jones \& Carpenter, 1986), indicating unmet social desires.

If, on average, shy people desire equal social contact to the less shy, why do they act in avoidant and inhibited ways? Schlenker and Leary, (1982; see also Leary \& Buckley, 2000) used self-presentation theory (Goffman, 1959) to answer this question. From this perspective, shy individuals, like most people, desire to make positive impressions. Shy individuals, however, doubt their ability to do so (Miller, 1995) because they doubt their social abilities more than the less shy (Alden \& Wallace, 1995). Specifically, shy people believe they possess poorer social skills (Miller, 1995) and less social competence (Jackson, Towson, \& Narduzzi, 1997) and effectiveness (Alden \& Cappe, 1981) than is objectively deserved (Alden \& Cappe, 1981; Melchior \& Cheek, 1990). Furthermore, shy people's beliefs concerning their inadequate social performance reflects negative biases related to others' evaluations (Stritzke, Nguyen, \& Durkin, 2004). Specifically, 
shy individuals interpret ambiguous interactions more negatively than do the less shy (Stopa \& Clark, 2000; Voncken, Bogels, \& de Vries, 2003), and thus perceive less approval or interest from others (McClure \& Nowicki, 2001; Winton, Clark, \& Edelmann, 1995). In sum, because shy individuals expect to fail socially and believe that others see them as social failures, they avoid social situations or act passively, and feel less close in relationships.

\section{Shyness, computer-mediated communication, and social networking services}

However, many social difficulties facing shy individuals appear limited to face-to-face communication (FtF). For example, not only do shy individuals report a greater preference for computer-mediated communication (CMC; e.g., electronic mail, instant messaging, textmessaging) over FtF (Pratarelli, Browne, \& Johnson, 1999), but they also behave in less shy ways (e.g., self-disclose more than normal; Brunet \& Schmidt, 2007; McKenna et al., 2002) communicating through CMC (Roberts et al., 2000). This has led some scholars to suggest that CMC might allow shy individuals to experience higherquality relationships (e.g., Brunet \& Schmidt, 2007; McKenna et al., 2002; Roberts et al., 2000).

Social networking services (e.g., Facebook.com, Myspace.com) are one form of CMC that may help shy individuals form quality relationships. Social networking services are websites that allow individuals to learn about and communicate with other users. Most services also allow users to establish a profile containing personal information (e.g., interests, religious and political beliefs, hobbies), indicate other users with whom they share a connection (i.e., friends), send private messages to other users, leave publicly viewable messages on others' profiles, join social groups, and organize social gatherings (Boyd \& Ellison, 2007).

Social networking services have become immensely popular, as $65 \%$ of teenagers and $35 \%$ of adults use one or more services (Pew Internet and American Life Project, 2009). Most users report that these services help them connect with old and current friends (Ellison, Steinfield, \& Lampe, 2007; Lampe, Ellison, \& Steinfield, 2006; Raacke \& Bonds-Raacke, 2008). Users often have greater social capital (i.e., resources obtained through social networks) than non-users (Ellison et 
al., 2007) and report using the websites to feel closer with others (Raacke \& Bonds-Raacke, 2008).

Social networking services may facilitate intimacy between peers. The amount of information available (e.g., hobbies, favorite books, religious and political views) makes it easy to learn about, and disclose to, others. Given that learning about others and disclosing personal information often leads to greater intimacy (Altman \& Taylor, 1973; Collins \& Miller, 1994), using social networking services that allow personal information exchanges may facilitate relational development. These sites also allow multiple modes of communication (i.e., public messages, private asynchronous messages similar to email, and private synchronous messages similar to instant messages) that may meet different communication needs. Because people often choose their mode of communication based on situational needs (e.g., speed of desired response, the number of recipients, privacy needs; Licoppe \& Smoreda, 2005), the multiple communication modes of these websites facilitate more frequent communication, creating feelings of intimacy (Hu, Wood, Smith, \& Westbrook, 2004).

Although social networking services provide an inviting space for peer interactions (Raacke \& Bonds-Raacke, 2008), shy individuals may find these websites especially valuable. Unlike the less shy, who can easily achieve peer intimacy FtF, shy individuals' FtF interaction difficulties leave them with fewer means of achieving intimacy. Shy individuals may be more likely to achieve peer closeness via social networking services than the less shy for several reasons. First, shy individuals prefer (Pratarelli et al., 1999), and are less shy when using (Roberts et al., 2000), CMC. Because shy people's social behaviors that foster intimacy (e.g., self-disclosure) are less inhibited with CMC, greater closeness may result. Second, shy people may feel greater control over self-presentation on social networking services because of its slower pace (Jacobson, 1999; Roberts et al., 2000), allowing more time to construct and revise messages. Third, these services provide resources that may help shy people feel greater comfort with their social skills. For example, shy individuals frequently report difficulty with finding a discussion topic (Manning \& Ray, 1993). However, individuals' social networking profiles typically contain considerable personal information, making it easier for shy people to find conversation topics. Fourth, similar to other CMC forms, social networking services lack most nonverbal behavior (McKenna et al., 
2002). Given a dearth of these behaviors, there are fewer negative cues for shy individuals to detect (Stritzke et al., 2004) and, therefore, they are more likely to express themselves (Sheeks \& Birchmeier, 2007). In sum, we predict that using social networking services to interact with friends will positively correlate with friendship quality and that this association should be particularly strong among shy individuals.

\section{The current study}

The present study examines the role of Facebook (http://www.facebook.com) in university students' social networks. When these data were collected in 2006, Facebook was a widely used (> 4 million users; Chris Hughes, Facebook spokesperson, personal communication, September 7, 2005) online social networking service tailored to university students and included features such as creating personal profiles, sending private and public messages, and joining social groups. However, it still did not have many now common features (e.g., games, surveys, and allowing multiple pictures). University students represent an ideal sample for this study for three reasons. First, university students are familiar with CMC (Jones \& Madden, 2002). Second, friendships are particularly important to university students (Keating, 1990) and Facebook is used primarily for interacting with friends (Pew Internet and American Life Project, 2009). Third, compared to the less shy, shy individuals report lowerquality friendships during college (Asendorpf, 2000), making it critical to examine how they can experience greater closeness with their friends.

We hypothesize that shyness levels will interact with frequency of Facebook use to predict the satisfaction, importance, and closeness of friendships. Specifically, for those with relatively low levels of shyness, Facebook use will be relatively unrelated to friendship qualities. Among those with relatively high shyness levels, Facebook use will relate positively to friendship quality. We expect that this pattern will only hold for Facebook friends. We expect that shy people's use of Facebook will be unrelated to the relationship quality of individuals with whom they do not interact on Facebook.

We hypothesize a similar interaction between shyness and Facebook use on perceived available social support from friends. 
Specifically, among people with low levels of shyness, Facebook use will be unrelated to social support, but among relatively shy individuals, Facebook use will be positively related to social support.

If Facebook use is associated with greater relationship satisfaction, importance, closeness, and social support, for shy individuals, then Facebook use should be related to beliefs about the sufficiency of one's personal relationships. As such, we hypothesize an interaction between shyness and Facebook use on loneliness such that, among those with relatively little shyness, Facebook use will be unrelated to loneliness, but among relatively shy individuals, Facebook use will be negatively associated with loneliness.

Finally, if Facebook use predicts shy individuals' friendship quality, support, and loneliness, it is important to determine if shyness influences why individuals use Facebook. To examine this, we asked participants to provide three reasons why they use Facebook. We hypothesize that shyness will be positively associated with reporting that Facebook has been used to gain knowledge about others, feeling closer to others because of Facebook, and feeling more comfortable with others offline because of Facebook.

\section{Method}

\section{Participants}

Participants consisted of 241 undergraduate students attending a mid-sized, private, Midwestern US university. Data from 17 participants were excluded from all analyses due to missing data or improper responding and 17 were excluded who did not use Facebook. Of the 207 remaining participants ( $n=69$ males and 138 females), $177(86 \%)$ were White or Caucasian, 8 (4\%) Hispanic or Latino(a), 10 (5\%) Asian American, 4 (2\%) Black or African American, and 8 (4\%) another or mixed ethnicity. Participants' mean age was 19.19 years $(\mathrm{SD}=1.70)$.

\section{Procedure}

Participants were recruited from an undergraduate pool and were offered extra credit for their participation. After providing 
NOT THE PUBLISHED VERSION; this is the author's final, peer-reviewed manuscript. The published version may be accessed by following the link in the citation at the bottom of the page.

informed consent, participants completed randomly-ordered measures on a laboratory computer.

\section{Measures}

Shyness. The 20-item Revised Cheek and Buss Shyness Scale (Cheek \& Melchior, 1985; RCBSS) assessed participants' shyness (e.g., I am often uncomfortable at parties and other social gatherings). Each item was accompanied by a 5-point Likert scale ( $1=$ very uncharacteristic or untrue, strongly disagree, $5=$ very characteristic or true, strongly agree). Item scores were averaged to yield shyness scores. The RCBSS demonstrated high internal reliability $(a=.91)$.

Friendship quality. A modified version of Asendorpf and Wilpers' (1998) relationship questionnaire assessed friendship quality. First, participants were asked to list the initials of all the people in their lives that they consider important. Next, they reported the relationship type for each person (e.g., parent, friend) and whether or not they interacted with him/her on Facebook. Participants reported their relationship satisfaction ("how satisfied are you with the time you spend with this person?"), relationship importance ("how important do you consider this relationship?"), and closeness ("how close are you with this person?") for each person on a 7-point Likert scale ( $1=$ never, not very, $7=$ always, very). Given that the relationships of each participant should not necessarily be expected to be equal in quality, internal consistency is not reported.

Items were averaged to assess (i) relationship satisfaction, (ii) importance, and (iii) closeness for friends with whom they interacted on Facebook, as well as (iv) relationship satisfaction, (v) importance, and (vi) closeness for friends for whom they had no Facebook interaction. Non-friends (e.g., family members) were excluded from all analyses because Facebook was used primarily between peers at the time the study was conducted. Of the participants, 182 described at least one friend with whom they interacted on Facebook and 123 reported on at least one friend with whom they did not interact on Facebook.

We also included several questions on participants' interactions on, and use of, Facebook. Items were accompanied by 7-point Likert scale ( $1=$ no, not at all, 7 = yes, a lot) (e.g., "How much do you think 
Facebook helped you get to know this person better?" "How much do you think Facebook helped you get closer to this person?" "Did Facebook help you feel more comfortable talking to this person offline?". Items were accompanied by 7-point Likert scale $(1=$ no, not at all, 7 = yes, a lot).

Perceived social support. The friend subscale of the Multidimensional Scale of Perceived Social Support (MSPSS; Zimet, Dahlem, Zimet, \& Farley, 1988) assessed participants' subjective assessment of available social support. Item scores, provided on 7point Likert scales, ( 1 = very strongly disagree, $7=$ very strongly agree) were averaged. Reliability of the MSPSS was strong ( $a=.94$ ).

Loneliness. The UCLA Loneliness Scale (Version 3; Russell, 1996) assessed loneliness (e.g., How often do you feel that you lack companionship?). Item scores were averaged and based on a 4-point Likert scale, ( $1=$ Never, $4=$ Always). In the current study, the scale's reliability was strong $(a=.92)$.

Facebook use. Participants indicated how many minutes per week they spent on Facebook.

\section{Results}

Table 1 provides descriptive statistics for, and intercorrelations among, all variables. Facebook use was strongly positively skewed so a logarithmic transformation was performed to normalize the data. Although descriptive statistics for Facebook use were based on raw scores (Table 1), all analyses used transformed scores. Shyness was negatively correlated to friendship satisfaction, importance, and closeness for both friends with whom they did and did not interact via Facebook. Support received from friends was negatively correlated with loneliness. Facebook use was positively correlated with closeness with friends with whom they interact on Facebook and the support received from friends. Although consistent with previous research (e.g., Jones \& Carpenter, 1986), these analyses do not address Facebook use as moderating the relationship between shyness and friendship quality. 


\section{Friendship satisfaction, closeness, and importance}

To test the primary hypotheses, we conducted hierarchical regressions in which each criterion variable (satisfaction, importance, and closeness of Facebook friends and non-Facebook friends) were regressed onto mean-centered Facebook use scores and meancentered shyness scores in the first step and their interaction in the second step (See Table 2).

Satisfaction. For satisfaction with Facebook friends, the first block was significant and shyness negatively predicted friend satisfaction. The second block added to the model as the interaction of shyness and Facebook use was marginally significant. As expected, Facebook use was positively related to satisfaction with Facebook friends among relatively shy individuals $(\beta=.19, p=.04)$ but not for those lower in shyness $(\beta=-.06, p=.60)$.

Regarding satisfaction with non-Facebook friends, the first block was significant and shyness was negatively associated with satisfaction. As predicted, the second block did not significantly add to the model as the interaction of shyness and Facebook usage was significant.

Importance. Regarding the importance of Facebook friends, the first block was significant and shyness negatively predicted friend importance. The second block significantly added to the model as the interaction of shyness and Facebook use was significant. Figure 1 shows the interaction using shyness and Facebook usage at one standard deviation above and below the mean. As expected, Facebook usage predicted greater importance of friends with whom they interact on Facebook among individuals relatively high in shyness $(\beta=.19, p=$ .04 ) but predicted marginally less importance among the relatively less shy $(\beta=-.18, p=.10)$.

For the importance of non-Facebook friends, the first block was significant with shyness being a negative predictor. However, as expected, the second block did not significantly add to the model as the interaction of shyness and Facebook usage was significant.

Closeness. For closeness to Facebook friends, the first block was significant and shyness negatively predicted, and Facebook use 
positively predicted, closeness. The second block significantly added to the model, as the shyness by Facebook use interaction was significant (see Figure 2). As expected, Facebook use predicted greater closeness to Facebook friends for the relatively shy $(\beta=.44, p<.01)$ but not among those relatively less shy $(\beta=-0.12, p=.25)$.

When reporting closeness to non-Facebook friends, the first block was significant and shyness negatively predicted closeness. As expected, the second block did not significantly add to the model as the interaction of shyness and Facebook use was not significant.

Perceived social support from friends. For social support received from friends, the first block was significant and shyness negatively predicted perceived support and Facebook use marginally positively predicted social support from friends. The second block significantly added to the model as the shyness by Facebook use interaction was significant.

Figure 3 shows the interaction using shyness and Facebook usage at one standard deviation above and below the mean. As expected, Facebook use predicted greater support from friends for the relatively shy $(\beta=.21, p=.01)$ but not among the relatively less shyness $(\beta=-.04, p=.70)$.

Loneliness. For loneliness, the first block was significant and shyness positively predicted loneliness. Counter to predictions, however, the second failed to add to the model as the interaction of shyness and Facebook use was not significant.

Shyness and use of Facebook for social interactions. Shyness was positively correlated to perceptions of gaining knowledge about others from using Facebook, $r(89)=.25, p=.02$ ) and feeling closer to others because of Facebook, $r(82)=.35, p<.01$. Among individuals who reported using Facebook more than one hour per week ( $n=103)$, shyness was not correlated with feeling more comfortable offline because of Facebook use $(r(85)=.12, p=.25)$.

\section{Discussion}

Online social networking services have recently emerged as popular ways to share personal information and communicate with 
friends. The current study tested the notion that Facebook use is associated with increased friendship quality for relatively shy individuals. Consistent with predictions, among relatively shy individuals, Facebook use was positively associated with satisfaction, importance, and closeness with Facebook friends, but not with nonFacebook friends. For relatively shy individuals, Facebook use was also associated with increased social support received from friends. In contrast, for relatively less shy individuals, Facebook use was not associated with satisfaction, importance, or closeness with nonFacebook friends, nor was it associated with social support. Indeed, participants reported relatively high friendship satisfaction, importance, closeness, and social support regardless of Facebook use. Importantly, those relatively shy individuals who reported high Facebook use had similar levels of friendship satisfaction, closeness, and importance (for Facebook friends) as their less shy counterparts.

These results extend our knowledge of shyness and CMC in important ways. Previous studies showed that shy individuals prefer interacting through CMC (Pratarelli, et al., 1999) and behave in less shy ways when interacting through CMC (Roberts et al., 2000), but had not shown how CMC might influence the quality of shy people's friendships. Furthermore, our results refute warnings (e.g., Carducci \& Zimbardo, 1995) that CMC use might cause shy individuals to become even more socially withdrawn and isolated. The current data clearly demonstrate that shy individuals' use of Facebook is associated with better quality friendships.

Why might Facebook facilitate satisfaction, closeness, and importance of, and support from, Facebook friends? First, shyness related positively to reports that Facebook helped people get to know others better. Information gained via Facebook might be especially important to shy people, as they likely know less about peers because of avoiding or withdrawing from social situations (e.g., Alden \& Phillips, 1990; Hill, 1989), and, thus, worry about having adequate conversation topics (Manning \& Ray, 1993). Second, shy individuals are more likely to report that, because of Facebook, they feel closer to peers. As shy individuals have difficulty achieving intimacy FtF (Asendorpf, 2000; Jones \& Carpenter, 1986), Facebook likely facilitates intimacy because they feel more comfortable with CMC (Roberts et al., 2000). Third, shy individuals' reports of a lack of social support may occur because they typically spend less time 
communicating with peers (e.g., Asendorpf, 2000). If shy people feel more comfortable communicating with $\mathrm{CMC}$, however, they may spend more time communicating via Facebook than FtF. However, given the study's cross-sectional design, we can only speculate about the mechanisms behind the association between Facebook use and better friendships among shy individuals.

Despite relatively shy individuals' reports that Facebook use was associated with better satisfaction, perceived closeness, and importance for, and greater perceived social support from, friends, Facebook use was not associated with less loneliness. This finding contrasts previous research that has shown that social support and closeness are negatively associated with loneliness (Kara \& Mirici, 2004). However, this might reflect the finding that, for relatively shy individuals, Facebook usage was not associated with satisfaction, intimacy and closeness with all friends - just those with whom they interacted with via Facebook. It is also possible that this unexpected finding is due to the cross-sectional design of the study. In fact, previous research (Kraut et al., 2002) has shown that, although Internet use is positively associated with initial loneliness, over time it leads to decreases in loneliness. It is possible that we might have found similar decreases in a longitudinal study of Facebook usage. Also, given that shyness was not correlated with reporting that Facebook was useful for feeling comfortable with others offline, Facebook might not help shy individuals transfer the feelings of comfort they feel talking with others online to comfort talking offline. As such, they might still experience loneliness if they are not physically interacting with friends. Clearly, future work needs to identify how, and under what conditions, online communication facilitates offline communication among shy individuals.

\section{Limitations and future directions}

Despite the current findings, there are limitations to the current study. Participants came from a convenience sample recruited from undergraduate psychology courses at a mid-sized, private, Midwestern US university. As such, participants were homogeneous in age and ethnicity. Although Facebook was primarily used by university students when these data were collected, Facebook has since become increasingly popular among other groups (e.g., older adults, high 
school students). We do not know how far the current findings would generalize and future research should examine the benefits of Facebook among different groups of shy individuals. Furthermore, because individuals use Facebook primarily to communicate with people they also interact with offline (Lampe et al., 2006), research should differentiate friendships that are exclusively CMC from those that involve both FtF and CMC interactions. Finally, future research should examine variables that may serve as moderators (e.g., friendship length, the amount of time spent communicating both on and off Facebook).

The most important limitation was the study's cross-sectional design. Although it provides valuable insights, it cannot speak to the long-term benefits, or detriments, of online social network use for the relatively shy. However, prior research suggests that Facebook use may have long-term benefits. For example, previous research has demonstrated that Internet use led to larger social networks, more FtF communication, and greater involvement in community activities (Kraut et al., 2002) and individuals high in social anxiety developed close, lasting, relationships online (McKenna et al., 2002). Similarly, several studies (McKenna et al., 2002; Roberts et al., 2000) demonstrated shyness decreases as CMC use increases. This suggests that that shy Facebook users may experience better quality relationships with Facebook friends both on- and offline. It is possible that CMC might improve exclusively FtF relationships, if shyness diminishes with increased Facebook use. Future research should examine the extent to which shy individuals' better Facebook friendship satisfaction, perceived closeness, and importance can be maintained over time.

Social networking sites are increasingly popular among all population strata and are changing how people initiate and maintain relationships (Ellison, et al., 2007; Lampe et al., 2006; Raacke \& Bonds-Raacke, 2008). It is important to understand how these online communities shape social interactions and networks. The present study suggests immediate benefits of Facebook use, especially for shy individuals, as it allows social interaction in a comfortable context. We encourage researchers to continue exploring how people's relationships and social interactions occur in the online world. 
NOT THE PUBLISHED VERSION; this is the author's final, peer-reviewed manuscript. The published version may be accessed by following the link in the citation at the bottom of the page.

\section{Acknowledgements}

The authors thank Steve Franzoi, Astrida Kaugars, and James K. McNulty for their helpful suggestions, as well as Jacqueline Howard, Ramona Bitanga, Stephanie Perry, and Elizabeth Angeli for their assistance with data collection. This study was conducted as the first author's masters thesis under the direction of the second author. Stephen Marks was the Action Editor on this article.

\section{Conflict of interest statement}

The author(s) declared no conflicts of interest with respect to the authorship and/or publication of this article.

\section{Funding}

This research received no specific grant from any funding agency in the public, commercial, or not-for-profit sectors.

\section{Corresponding author}

Levi R. Baker, Department of Psychology, Austin Peay Building - Room 311B, University of Tennessee, Knoxville, TN 37996, USA, Email:

levirbaker@gmail.com

\section{References}

Alden, L., \& Cappe, R. (1981). Nonassertiveness: Skill deficit or selective selfevaluation? Behavior Therapy, 12, 107-114.

Alden, L. E., \& Phillips, N. (1990). An interpersonal analysis of social anxiety and depression. Cognitive Therapy and Research, 14, 499-512.

Alden, L. E., \& Wallace, S. T. (1995). Social phobia and social appraisal in successful and unsuccessful social interactions. Behaviour Research and Therapy, 33, 497-505.

Altman, I., \& Taylor, D. (1973). Social penetration: The development of interpersonal relationships. New York: Holt, Rinehart and Winston.

Arkowitz, H., Hinton, R., Perl, J., \& Himadi, W. (1978). Treatment strategies for dating anxiety in college men based on real-life practice. Counseling Psychologist, 7, 41-46.

Asendorpf, J. B. (1990). Beyond social withdrawal: Shyness, unsociability and peer avoidance. Human Development, 33, 250-259.

Asendorpf, J. B. (2000). Shyness and adaptation to the social world of university. In W. R. Crozier (Ed.), Shyness: Development, consolidation and change (pp. 103-120). New York: Routledge.

Asendorpf, J. B., \& Wilpers, S. (1998). Personality effects on social relationships. Journal of Personality and Social Psychology, 74, 15311544. 
Boyd, D., \& Ellison, N. B. (2007). Social network sites: Definition, history, and scholarship. Journal of Computer-Mediated Communication, 13.

Retrieved from http://jcmc.indiana.edu/vol13/issue1/boyd.ellison.html

Brunet, P. M., \& Schmidt, L. A. (2007). Is shyness context specific? Relation between shyness and online self-disclosure with and without a live webcam in young adults. Journal of Research in Personality 41, 938945.

Buss, A. H. (1986). A theory of shyness. In W. H. Jones, J. M. Cheek, \& S. R. Briggs (Eds.), Shyness: Perspectives on research and treatment (pp. 39-46). New York: Plenum Press.

Carducci, B. J., \& Zimbardo, P. G. (1995). Are you shy? Psychology Today, $28,34-45,64-70,78-82$.

Cheek, J. M., \& Busch, C. M. (1981). The influence of shyness on loneliness in a new situation. Personality and Social Psychology Bulletin, 7, 572577.

Cheek, J. M., \& Buss, A. H. (1981). Shyness and sociability. Journal of Personality and Social Psychology, 41, 330-339.

Cheek, J. M., \& Melchior, L. A. (1985). Measuring the three components of shyness. In M. H. Davis \& S. L. Franzoi (Co-chairs), Emotion, personality, and personal well-being II. Symposium conducted at the annual convention of the American Psychological Association, Los Angeles.

Collins, N., \& Miller, L. (1994). Self-disclosure and liking: a meta-analytic review. Psychological Bulletin, 116, 457-475.

Dodge, C. S., Heimberg, R. G., Nyman, D., \& O'Brien, G. T. (1987). Daily heterosocial interactions of high and low socially anxious college students: A diary study. Behavior Therapy, 18, 90-96.

Ellison, N., Steinfield, C., \& Lampe, C. (2007). The benefits of Facebook 'friends': Exploring the relationship between college students' use of online social networks and social capital. In Journal of ComputerMediated Communication, 12. Retrieved from http://jcmc.indiana.edu/vol12/ issue4/ellison.html

Garcia, S., Stinson, L., Ickes, W., Bissonnette, V., \& Briggs, S.R. (1991).Shyness and physical attractiveness in mixed-sex dyads. Journal of Personality and Social Psychology, 61, 35-49.

Goffman, E. (1959). The Presentation of self in everyday life. New York: Anchor.

Heimberg, R. G., Harrison, D. F., Montgomery, D., Madsen, C. H., Jr., \& Sherfey, J. A. (1980). Psychometric and behavioral analyses of a social anxiety inventory: The Situation Questionnaire. Behavioral

Assessment, 2, 403-415.

Journal of Social and Personal Relationships, Vol 27, No. 7 (November 2010): pg. 873-889. DOI. This article is @ SAGE Publications and permission has been granted for this version to appear in e-Publications@Marquette. SAGE Publications does not grant permission for this article to be further copied/distributed or hosted elsewhere without the express permission from SAGE Publications. 
Hill, G. J. (1989). An unwillingness to act: Behavioral appropriateness, situational constraint, and self-efficacy in shyness. Journal of Personality, 57, 871-890.

Hu, Y., Wood, J. F., Smith, V., \& Westbrook, N. (2004). Friendships through IM: Examining the relationship between instant messaging and intimacy. Journal of Computer-Mediated Communication, 10(1). Retrieved from http://jcmc.indiana.edu/vol10/issue1/hu.html

Jacobson, D. (1999). Impression formation in cyberspace: Online expectations and offline experiences in text-based virtual communities. Journal of Computer-Mediated Communication, 5(1). Retrieved from http://jcmc.indiana.edu/vol5/issue1/jacobson.html

Jackson, T., Towson, S., \& Narduzzi, K. (1997). Predictors of shyness: A test of variables related to self-presentation models. Social Behavior and Personality, 25, 149-154.

Jones, W. H., \& Carpenter, B. N. (1986). Shyness, social behavior, and relationships. In W. H. Jones, J. M. Cheek \& S. R. Briggs (Eds.), Shyness: Perspectives on research and treatment (pp. 227-38). New York: Plenum.

Jones, S., \& Madden, M. (2002). The internet goes to college: How students are living in the future with today's technology. Retrieved November 12th, 2005 from http://www.pewinternet.org/pdfs/PIP_College_Report.pdf

Kara, M., \& Mirici, A. (2004). Loneliness, depression, and social support of Turkish patients with chronic obstructive pulmonary disease and their spouses. Journal of Nursing Scholarship, 36, 331-336.

Keating, D. P. (1990). Adolescent thinking. In S. S. Feldman \& G. R. Elliott (Eds.), At the threshold: The developing adolescent. Cambridge MA: Harvard University Press.

Kraut, R., Kiesler, S., Boneva, B., Cummings, J. N., Helgeson, V., \& Crawford, A. M. (2002). Internet paradox revisited. Journal of Social Issues, 58, 49-74.

Lampe, C., Ellison, N., \& Steinfield, C., (2006). A Face(book) in the crowd: Social searching vs. social browsing. Proceedings of the 2006 20th Anniversary Conference on Computer Supported Cooperative Work (pp. 167-170). New York: ACM Press.

Leary, M. R., \& Buckley, K. E. (2000). Shyness and the pursuit of social acceptance. In W. R. Crozier (Ed.), Shyness: Development, consolidation and change (pp. 103-120). New York: Routledge.

Leary, M. R., \& Kowalski, R. M. (1995). Social anxiety. New York: Guilford Press.

Leary, M. R., Knight, P. D., \& Johnson, K. A. (1987). Social anxiety and dyadic conversation: A verbal response analysis. Journal of Social and Clinical Psychology, 5, 34-50.

Journal of Social and Personal Relationships, Vol 27, No. 7 (November 2010): pg. 873-889. DOI. This article is @ SAGE Publications and permission has been granted for this version to appear in e-Publications@Marquette. SAGE Publications does not grant permission for this article to be further copied/distributed or hosted elsewhere without the express permission from SAGE Publications. 
Licoppe, C., \& Smoreda, Z. (2005). Are social networks technologically embedded? How networks are changing today with changes in communication technology. Social Networks, 27, 317-335.

Mandel, N. M., \& Shrauger, J. (1980). The effects of self-evaluative statements on heterosocial approach in shy and nonshy males. Cognitive Therapy and Research, 4, 369-381.

Manning, P., \& Ray, G. (1993). Shyness, self-confidence, and social interaction. Social Psychology Quarterly, 56, 178-192.

McClure, E. B., \& Nowicki, S., Jr. (2001). Associations between social anxiety and nonverbal processing skill in preadolescent boys and girls. Journal of Nonverbal Behavior, 25, 3-19.

McCroskey, J. C. (1976). The effects of communication apprehension on nonverbal behavior. Communication Quarterly, 24, 39-44.

McKenna, K. Y. A., Green, A. S., \& Gleason, M. E. J. (2002). Relationship formation on the internet: What's the big attraction? Journal of Social Issues, 58, 9-31.

Melchior, L. A., \& Cheek, J. M. (1990). Shyness and anxious selfpreoccupation during a social interaction. Journal of Social Behavior \& Personality, 5, 117-130.

Meleshko, K. G., \& Alden, L. E. (1993). Anxiety and self-disclosure: Toward a motivational model. Journal of Personality and Social Psychology, 64, 1000-1009.

Miller, R. S. (1995). On the nature of embarrassability: Shyness, social evaluation and social skill. Journal of Personality, 63, 315-339.

Nelson, L. J., Padilla-Walker, L. M., Badger, S., Barry, C. M., Carroll, J. S., \& Madsen, S. D. (2008). Associations between shyness and internalizing behaviors, externalizing behaviors, and relationships in emerging adulthood. Journal of Youth and Adolescence, 37, 605-615.

Neto, F. (1992). Loneliness among Portuguese adolescents. Social Behavior and Personality, 20, 15-21.

Pew Internet and American Life Project. (2009). Adults and Social Network Websites. Retrieved March 11, 2009, from http://www.pewinternet.org

Pilkonis, P. A. (1977). The behavioral consequences of shyness. Journal of Personality, 45, 596-611.

Pratarelli, M. E., Browne, B. L., \& Johnson, K. (1999). The bits and bytes of computer/Internet addiction: A factor analytic approach. Behavior Research Methods, Instruments \& Computers, 31, 305-314.

Raacke, J., \& Bonds-Raacke, J. (2008). MySpace and Facebook: Applying the uses and gratifications theory to exploring friend-networking sites. CyberPsychology \& Behavior, 11, 169-174.

Roberts, L. D., Smith, L. M., \& Pollock, C. M. (2000). 'U r a lot bolder on the net': Shyness and internet use. In W. R. Crozier (Ed.), Shyness:

Journal of Social and Personal Relationships, Vol 27, No. 7 (November 2010): pg. 873-889. DOI. This article is @ SAGE Publications and permission has been granted for this version to appear in e-Publications@Marquette. SAGE Publications does not grant permission for this article to be further copied/distributed or hosted elsewhere without the express permission from SAGE Publications. 
Development, consolidation and change (pp. 121-138). New York: Routledge.

Russell, D. W. (1996). UCLA Loneliness Scale (version 3): Reliability, validity, and factor structure. Journal of Personality Assessment, 66, 20-40.

Schlenker, B. R., \& Leary, M. R. (1982). Social anxiety and self-presentation: A conceptualization model. Psychological Bulletin, 92, 641-669.

Schmidt, L.A., \& Fox, N.A. (1999). Conceptual, biological and behavioral distinctions among different types of shy children. In L. A. Schmidt \&

J. Schulkin (Eds), Extreme fear, shyness and social phobia: Origins, biological mechanisms, and clinical outcomes (pp. 47-66). New York: Oxford University Press.

Sheeks, M. S., \& Birchmeier, Z. P. (2007). Shyness, sociability, and the use of computer-mediated communication in relationship development. CyberPsychology \& Behavior, 10, 64-70.

Stopa, L., \& Clark, D. M. (2000). Social phobia and interpretation of social events. Behaviour Research and Therapy, 38, 273-283.

Stritzke, W. G. K., Nguyen, A., \& Durkin, K. (2004). Shyness and computermediated communication: A self-presentational theory perspective. Media Psychology, 6, 1-22.

Voncken, M. J., Bogels, S. M., \& de Vries, K. (2003). Interpretation and judgmental biases in social phobia. Behaviour Research and Therapy, $41,1481-1488$.

Weaver, J. (1987). Shyness: An inhibitor to the development of intimacy. Journal of Social Work and Human Sexuality, 5, 111-122.

Winton, E. C., Clark, D. M. \& Edelmann, R. J. (1995). Social anxiety, fear of negative evaluation and detection of negative emotion in others. Behaviour Research and Therapy, 33, 193-196.

Zimet, G. D., Dahlem, N. W., Zimet, S. G., \& Farley, G. K. (1988). The Multidimensional Scale of Perceived Social Support. Journal of Personality Assessment, 52, 30-41.

\section{Appendix}

\section{Table 1 Descriptive statistics and correlations}

\begin{tabular}{|c|c|c|c|c|c|c|c|c|c|c|}
\hline & 1 & 2 & 3 & 4 & 5 & 6 & 7 & 8 & 9 & 10 \\
\hline I. Shyness & - & & & & & & & & & \\
\hline 2. Facebook usage & .04 & - & & & & & & & & \\
\hline 3. Satisfaction (FB) & $-.20 * *$ & .07 & - & & & & & & & \\
\hline 4. Satisfaction (no FB) & $-.28^{* * *}$ & .05 & $.43 * *$ & - & & & & & & \\
\hline 5. Importance (FB) & $-.19 *$ & .02 & $.49 \%$ & .10 & - & & & & & \\
\hline 6. Importance (no FB) & $-.42^{* * k}$ & .05 & $.29 \% k$ & $.36^{\text {*ak }}$ & $.45^{* * *}$ & - & & & & \\
\hline 7. Closeness (FB) & $-.26 * *$ & $.18^{*}$ & $.50 \%$ & $.21^{*}$ & $.81^{* *}$ & $.44^{\text {*ik }}$ & - & & & \\
\hline 8. Closeness (no FB) & $-.25^{* * *}$ & .11 & $.20 *$ & $.34^{* * k}$ & $.39 \%$ & $.78^{\text {*k }}$ & $.50^{\text {\% }}$ k & - & & \\
\hline 9. Support from friends & $-.34 * *$ & .10 & $.23^{\text {*k }}$ & $.21 *$ & .10 & $.17^{\dagger}$ & $.13^{\dagger}$ & .14 & - & \\
\hline 10. Loneliness & $.58 * *$ & .04 & $-.33^{* *}$ & $-.25^{* * *}$ & $-.24 * *$ & $-.30^{* * *}$ & $-.26^{* * *}$ & $-.24 *$ & $-.51^{* *}$ & - \\
\hline M & 2.51 & 87.06 & 5.38 & 4.85 & 6.00 & 5.35 & 5.86 & 5.17 & 5.94 & 1.95 \\
\hline SD & .65 & 117.63 & 1.21 & 1.57 & 0.83 & 1.30 & 0.95 & 1.24 & 1.11 & .42 \\
\hline
\end{tabular}

Note. $+p<.10 ; * p<.05 ; * * p<.01$. "FB" stands for Facebook. 
NOT THE PUBLISHED VERSION; this is the author's final, peer-reviewed manuscript. The published version may be accessed by following the link in the citation at the bottom of the page.

Table 2 Effects of shyness, Facebook usage, and the interaction on relationship outcomes

\begin{tabular}{|c|c|c|c|c|c|c|c|c|}
\hline & \multicolumn{4}{|c|}{ Satisfaction (FB) } & \multicolumn{4}{|c|}{ Satisfaction (no FB) } \\
\hline & $F(d f)$ & Adj. $R^{2}$ & b & $\beta$ & $F(d f)$ & Adj. $R^{2}$ & b & $\beta$ \\
\hline Block 1 & $4.58(2,178)^{*}$ & .04 & & & $4.75(2,105)^{*}$ & .07 & & \\
\hline Shyness & & & -.4 & $-.21^{20 k}$ & & & -.69 & $-.29 * *$ \\
\hline Facebook & & & .23 & .09 & & & .21 & .07 \\
\hline Block 2 & $4.21(3,178)^{\text {tok }}$ & .05 & & & $3.24(3,105)^{*}$ & .06 & & \\
\hline \multirow[t]{3}{*}{ Shyness $x$} & ook & & .48 & $.14^{\dagger}$ & & & .22 & .05 \\
\hline & \multicolumn{4}{|c|}{ Importance (FB) } & \multicolumn{4}{|c|}{ Importance (no FB) } \\
\hline & $F(d f)$ & Adj. $R^{2}$ & $\mathrm{~b}$ & $\beta$ & $F(d f)$ & Adj. $R^{2}$ & b & $\beta$ \\
\hline Block 1 & $3.50(2,178)^{*}$ & .03 & & & $11.61(2,105)^{\text {*3k }}$ & .17 & & \\
\hline Shyness & & & -.25 & $-.20^{\text {jok }}$ & & & -.84 & $-.43^{* * 1}$ \\
\hline Facebook & & & .07 & .04 & & & .21 & .09 \\
\hline Block 2 & $4.87(3,178)^{\text {sk }}$ & .06 & & & $7.90(3,105)^{40 k}$ & .17 & & \\
\hline \multirow[t]{3}{*}{ Shyness $\times$} & ook & & .48 & $.21^{\text {冰 }}$ & & & .24 & .07 \\
\hline & \multicolumn{4}{|c|}{ Closeness (FB) } & \multicolumn{4}{|c|}{ Closeness (no FB) } \\
\hline & $F(d f)$ & Adj. $R^{2}$ & b & $\beta$ & $F(d f)$ & Adj. $R^{2}$ & b & $\beta$ \\
\hline Block 1 & $11.18(2,178)^{\text {*k* }}$ & .1 & & & $4.37(2,105)^{*}$ & .06 & & \\
\hline Shyness & & & -.42 & $-.28^{\text {*k }}$ & & & -.49 & $-.26 * *$ \\
\hline Facebook & & & .41 & $21^{* * ⿰ ㇇ ⿰ 亅 ⿱ 丿 丶 丶 ~}$ & & & .29 & .13 \\
\hline Block 2 & $14.56(3, \mid 78)^{\text {wak }}$ & .19 & & & $3.17(3,105)^{*}$ & .06 & & \\
\hline \multirow[t]{3}{*}{ Shyness $\times$} & ook & & .82 & $.31^{\text {ke }}$ & & & .28 & .09 \\
\hline & \multicolumn{4}{|c|}{ Social Support } & \multicolumn{4}{|c|}{ Loneliness } \\
\hline & $F(d f)$ & Adj. $R^{2}$ & b & $\beta$ & $F(d f)$ & Adj. $R^{2}$ & b & $\beta$ \\
\hline Block 1 & I $4.99(2,206)^{\text {) }}$ & .12 & & & $52.35(2,206)^{\text {*tok }}$ & .33 & & \\
\hline Shyness & & & -.59 & 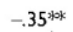 & & & .38 & .58 \\
\hline Facebook & & & .24 & $.11^{\dagger}$ & & & .02 & .02 \\
\hline Block 2 & II.43 $(3,206)^{\text {wok }}$ & .13 & & & $35.08(3,206)^{\text {*ak }}$ & .33 & & \\
\hline \multicolumn{3}{|c|}{ Shyness $\times$ Facebook } & .4 & $.14 *$ & & & .06 & .05 \\
\hline
\end{tabular}

Note. $+p<.10 ; *=p<.05 ; * *=p<.01$. "FB" stands for Facebook.

Journal of Social and Personal Relationships, Vol 27, No. 7 (November 2010): pg. 873-889. DOI. This article is (C SAGE Publications and permission has been granted for this version to appear in e-Publications@Marquette. SAGE Publications does not grant permission for this article to be further copied/distributed or hosted elsewhere without the express permission from SAGE Publications. 
NOT THE PUBLISHED VERSION; this is the author's final, peer-reviewed manuscript. The published version may be accessed by following the link in the citation at the bottom of the page.

Figure 1 Predicted importance of peers with whom they interact on Facebook by shyness and Facebook usage

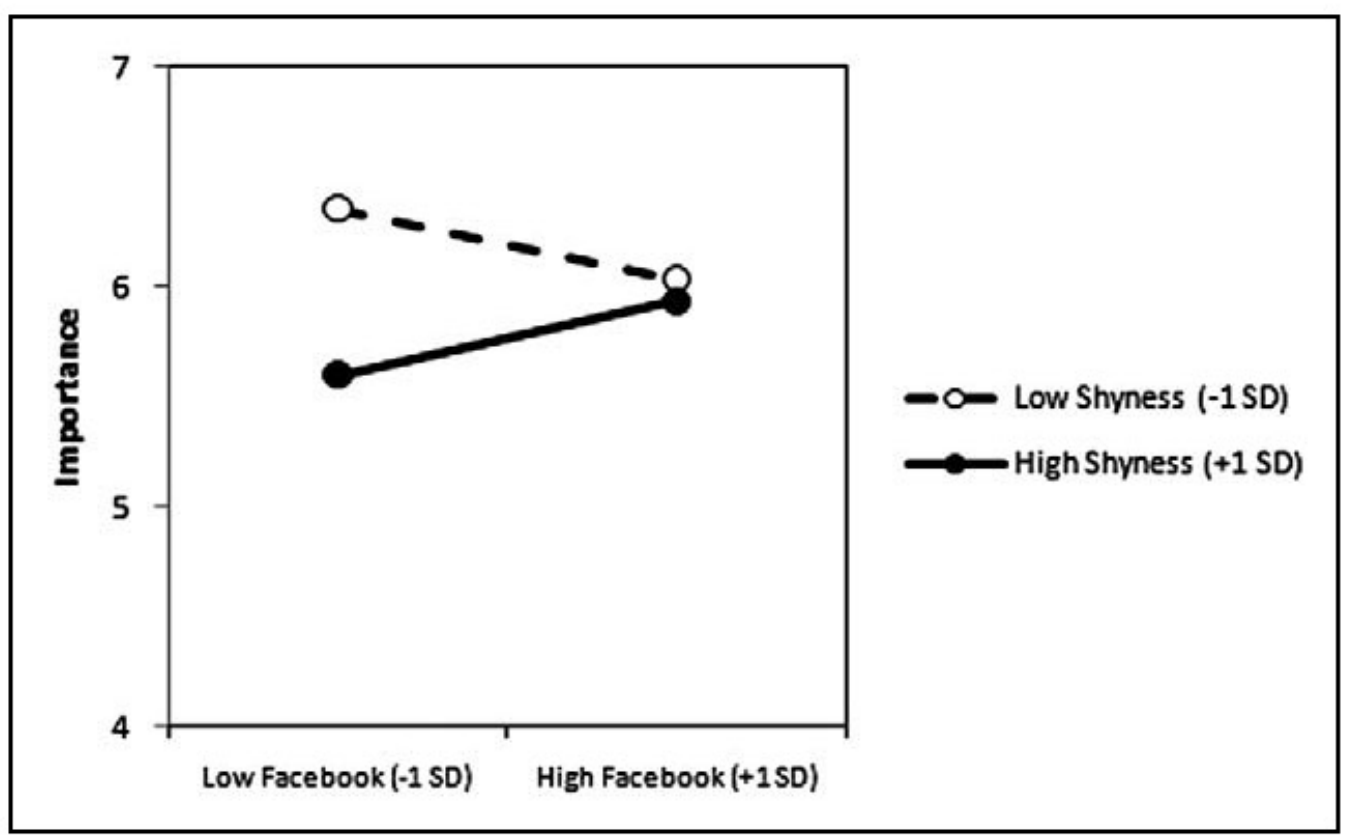

Figure 2 Predicted closeness with peers with whom they interact on Facebook by shyness and Facebook usage

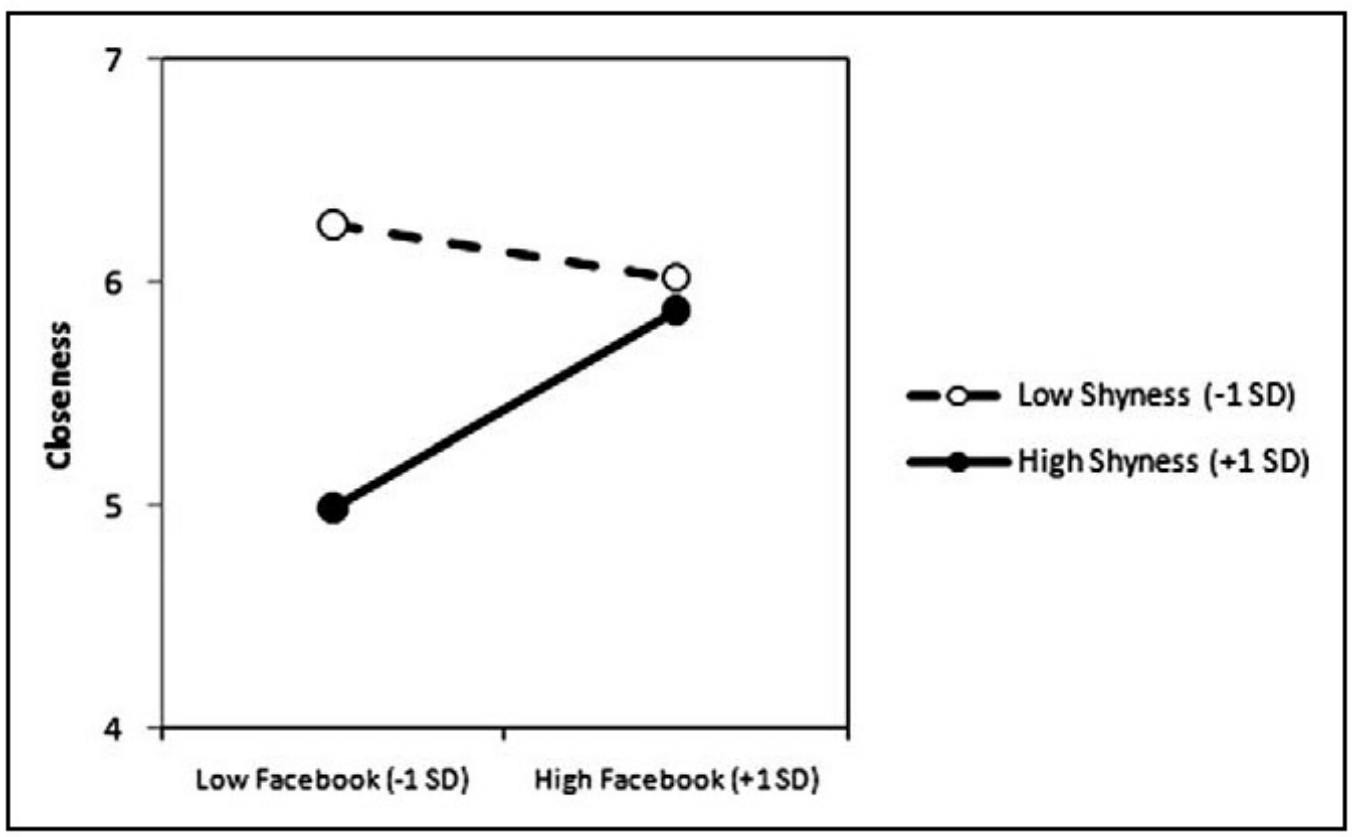

Journal of Social and Personal Relationships, Vol 27, No. 7 (November 2010): pg. 873-889. DOI. This article is (c) SAGE Publications and permission has been granted for this version to appear in e-Publications@Marquette. SAGE Publications does not grant permission for this article to be further copied/distributed or hosted elsewhere without the express permission from SAGE Publications. 
NOT THE PUBLISHED VERSION; this is the author's final, peer-reviewed manuscript. The published version may be accessed by following the link in the citation at the bottom of the page.

Figure 3 Predicted social support by shyness and Facebook usage

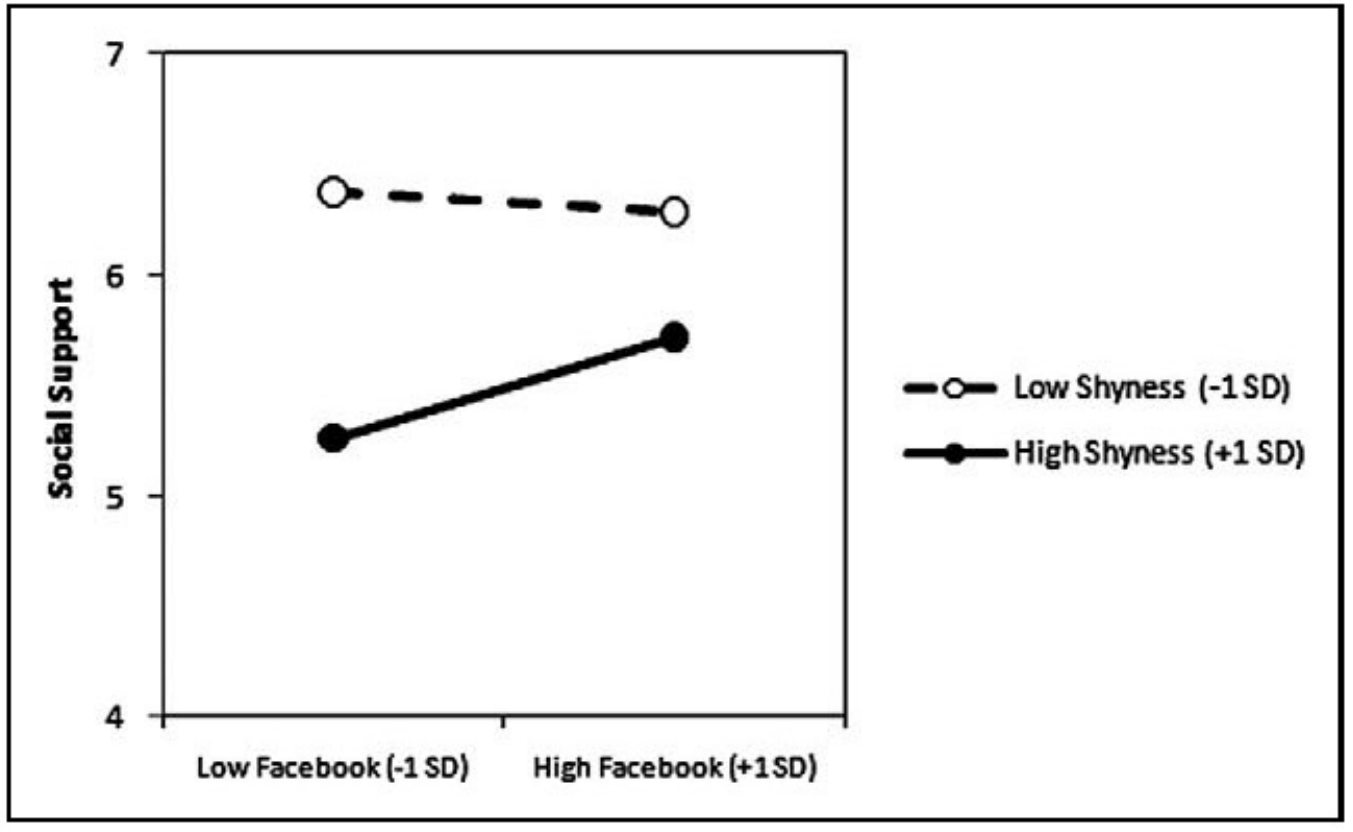

Journal of Social and Personal Relationships, Vol 27, No. 7 (November 2010): pg. 873-889. DOI. This article is @ SAGE Publications and permission has been granted for this version to appear in e-Publications@Marquette. SAGE Publications does not grant permission for this article to be further copied/distributed or hosted elsewhere without the express permission from SAGE Publications. 